\title{
Microvascular endothelial function and severity of primary open angle glaucoma
}

SMI Bukhari', KY Kiu', R Thambiraja', S Sulong ${ }^{2}$, AHG Rasool ${ }^{3}$ and AT Liza-Sharmini ${ }^{1}$

\begin{abstract}
Purpose The role of microvascular endothelial dysfunction on severity of primary open angle glaucoma (POAG) was investigated in this study.
\end{abstract} Patients and methods A prospective cohort study was conducted. One hundred and fourteen ethnically Malay patients (114 eyes) with POAG treated at the eye clinic of Hospital University Sains Malaysia between April 2012 and December 2014 were recruited. Patients aged between 40 and 80 years with two consecutive reliable and reproducible Humphrey visual field 24-2 analyses were selected. Patients who were diagnosed with any other type of glaucoma, previous glaucoma-filtering surgery, or other surgeries except uncomplicated cataract and pterygium surgery were excluded. Humphrey visual field analysis 24-2 was used to stratify the severity of glaucoma using Advanced Glaucoma Intervention Study (AGIS) score at the time of recruitment. Microvascular endothelial function was assessed using Laser Doppler fluximetry and iontophoresis. Iontophoresis process with acetylcholine (ACh) and sodium nitroprusside (SNP) was used to measure microvascular endotheliumdependent and -independent vasodilatation, respectively.

Results Based on the AGIS score, 55 patients showed mild glaucoma, with 29 moderate and 30 severe. There was statistically significant difference in microvascular endothelial function (ACh\% and $\mathrm{ACh}_{\max }$ ) between mild and moderate POAG cases $(P=0.023)$ and between mild and severe POAG cases $(P<0.001)$. There was negative correlation between microvascular endothelial function and severity of POAG $(r=-0.457, P<0.001)$.

Conclusion Microvascular endothelial dysfunction may have a role in influencing the severity of POAG in Malay patients.
Eye (2016) 30, 1579-1587; doi:10.1038/eye.2016.185; published online 19 August 2016

\section{Introduction}

Glaucoma is a complex multi-factorial disease leading to irreversible blindness. The pressuredependent (mechanical) and pressureindependent (vascular) theories have been postulated to have important role in glaucomatous optic neuropathy. ${ }^{1}$ Pressureindependent mechanism holds imbalance of the optic nerve head $(\mathrm{ONH})$ perfusion responsible for ischemia in the retinal nerve fiber layer (RNFL). 2,3

$\mathrm{ONH}$ perfusion may be affected by ocular perfusion pressure (OPP). OPP is dynamic but can be mathematically calculated using systemic blood pressure and intraocular pressure (IOP). OPP is affected by the resistance to flow and regulated by the size (caliber) of vessel lumen. ${ }^{4}$ The advancement of technology has made the visualization of ocular blood flow possible using various techniques: color Doppler ultrasound imaging, 5 scanning laser ophthalmoscopic angiography, ${ }^{6}$ confocal scanning laser Doppler flowmetry, ${ }^{7}$ and retinal vessel analyzer (RVA). ${ }^{8}$ These techniques measure different aspect of ocular blood flow but are not specific to quantify the blood flow to $\mathrm{ONH}$. There was also a lack of gold standard as reference. In addition, most techniques are expensive and require clear media and highly skilled, experienced technician. ${ }^{9-13}$ For example, RVA provides direct visualization of pulsation of large retinal vessels throughout cardiac cycle without measuring actual blood flow. ${ }^{14}$ RVA is used to quantify microvascular changes in systemic and ocular diseases. ${ }^{14,15}$ There were evidences of reduction in vascular diameter in glaucoma patients. ${ }^{15,16}$

Autoregulation is believed to be responsible for maintaining $\mathrm{ONH}$ perfusion. ${ }^{17,18}$ The basic mechanisms underlying autoregulation are still unclear. The proposed mechanisms include
${ }^{1}$ Department of

Ophthalmology, School of Medical Sciences, Universiti Sains Malaysia, Kota Bharu, Malaysia

${ }^{2}$ Human Genome Centre, School of Medical Sciences, Universiti Sains Malaysia, Kota Bharu, Malaysia

${ }^{3}$ Pharmacology Department, School of Medical Sciences, Universiti Sains Malaysia, Kota Bharu, Malaysia

\section{Correspondence:}

AT Liza-Sharmini,

Department of

Ophthalmology, School of

Medical Sciences, Universiti Sains Malaysia, Health

Campus, Jalan Raja

Perempuan Zainab II, Kota Bharu 16150,

Malaysia

Tel: +60 97676353 or

+60199179227;

Fax: +6097653370

E-mail: liza@usm.my or

sharminiliz@live.com

Received: 29 January 2016 Accepted in revised form: 26 June 2016

Published online: 19 August 2016 
metabolic, myogenic, neurogenic, and humoral factors in the ocular circulation. ${ }^{19,20}$ Endothelium acts as a mediator in regulating the vascular tone. Alterations in the local concentrations of metabolites such as oxygen, carbon dioxide, potassium, and hydrogen may influence ocular vascular tone. ${ }^{19}$ The hemodynamic response of the retinal vasculature to hyperoxia is thought to be mediated by endothelin. ${ }^{21}$ Endothelial-derived vasodilator factors are believed to be responsible for hypoxia-induced vasodilatation of the retinal vasculature. ${ }^{22}$ In general, myogenic autoregulation is considered to be mechanically independent of the endothelium. In the cerebral circulation, however, myogenic-induced vasoconstriction has also been suggested to be at least partly mediated by endothelial factors. ${ }^{23}$ Myogenic regulation has been found in the $\mathrm{ONH}$ and retina. ${ }^{24,25}$ Humoral control refers to the potential regulatory influence of numerous vasoactive agents present in the circulating blood. The effect is either through direct interaction with the vascular smooth muscle cells and pericytes or through mediation of endothelial cells causing changes in blood flow. ${ }^{26}$

Microvascular endothelial function can be assessed non-invasively using laser Doppler fluximetry (LDF) and the process of iontophoresis. LDF is a device that permits real-time continuous measurement of microvascular perfusion. ${ }^{27}$ Iontophoresis of acetylcholine (ACh) is used to assess endothelial-dependent vasodilatation, while sodium nitroprusside (SNP) iontophoresis assesses endothelial-independent vasodilatation. The LDF signal is a stochastic representation of the number of cells in the sample volume multiplied by their velocities. The output from the LDF is referred to as 'perfusion flux' ${ }^{28}$

Microvascular perfusion flux is the product of the number of blood cells and the mean velocity of blood cells. Mean velocity is proportional to blood flow.

Assuming proportionality between blood cells number and blood volume, the LDF signal should be linearly related to blood flow in the measured volume. In most physiological and clinical situations, LDF flux and volume flow have a good correlation. Many studies have demonstrated a good relationship between LDF measurements and other method of blood flow measurement, such as plethysmography. ${ }^{29}$ In LDF, the perfusion flux is expressed in terms of arbitrary unit, which do not gives the absolute blood perfusion unit. Measurement of blood perfusion by LDF is therefore less valuable in comparing absolute values of blood perfusion between individuals. However, intraindividual and interindividual comparison of dynamic response to standardized stimuli such as transient ischemic block and local warming can be made.

Microvascular endothelial dysfunction may accelerate the glaucomatous damage especially in the presence of uncontrolled IOP. ${ }^{30,3}$ More pronounced reduction of
ONH blood flow velocities was noted in glaucoma patients with visual field progression when compared with those with non-progression. ${ }^{31}$ Eyes with progressive visual field defects in patients with normal-tension glaucoma had lower blood flow velocities and higher resistive index in the central retinal artery and the short posterior ciliary arteries than did those with stable visual field defects. ${ }^{31,32}$ There is little knowledge on glaucoma in the Malay population. In addition, there is evidence of the effects of ethnicity on clinical presentation and progression of glaucoma. ${ }^{33,34}$ The objective of this study was to determine the association between microvascular endothelial dysfunction and severity of primary open angle glaucoma (POAG) in Malay patients. Predictors affecting microvascular endothelial dysfunction in Malay patients with POAG were also evaluated.

\section{Materials and methods}

A prospective cohort study was conducted involving 114 Malay patients diagnosed with POAG (114 eyes). These patients were recruited from the glaucoma clinic of Hospital Universiti Sains Malaysia between April 2012 and December 2014. Written consent was obtained after full explanation was given to patients. This study received approval from the research and ethics committee of the School of Medical Sciences, Universiti Sains Malaysia and was conducted in accordance to the Declaration of Helsinki for human research.

POAG is defined according to Asia Pacific Glaucoma Guideline. ${ }^{35}$ Patients aged between 40 and 80 years with two consecutive reliable (false positive and negative $<33 \%$, fixation loss $<20 \%$ ) and reproducible Humphrey visual field 24-2 analyses were selected. Visual field assessment was either conducted within 3 months from the recruitment period or obtained from the medical record of the selected patients. Visual field assessments obtained from the medical record were obtained no more than 6 months before the recruitment period. Patients who were diagnosed with any other type of glaucoma (eg, steroid induced, pseudoexfoliative, and pigmentary glaucoma) were excluded. POAG patients presented with history of previous glaucoma-filtering surgery or other surgeries except uncomplicated cataract and pterygium surgery were excluded. Those with underlying ocular conditions which may interfere with visual field interpretation, were also excluded: media opacities, including cataract (visual acuity $<6 / 60$ ), vitreous hemorrhage, post-pan-retinal photocoagulation, tilted disc, and retinal disease. Those with uncontrolled IOP or failed to achieve target pressure were also excluded. If both eyes were deemed eligible, only the right eye was selected regardless of the severity of glaucoma. 
Assessment of the severity of POAG was based on modified Advanced Glaucoma Intervention Study (AGIS) scoring system on Humphrey visual field 24-2 analysis. ${ }^{36}$ Only one of the two consecutive reliable and reproducible visual fields was selected for AGIS scoring. Primary scoring was conducted by the primary investigator (SMIB) and secondary scoring by the glaucoma specialist (L-SAT). Both investigators were masked. The final score was based on the average of the scoring of two investigators. Glaucoma patients were stratified into mild $(0-5)$, moderate (6-11), and severe (12-20) categories based on the modified scoring system. IOP was also obtained during the recruitment period using Goldmann applanation tonometry (Haag Streit, Koeniz, Switzerland) at sitting position by another investigator (KKY) between 0800 and 1200 hours.

Selected patients were asked to refrain from smoking, eating salty foods, and drinking alcohol and caffeinated beverages for at least $10 \mathrm{~h}$ before the vascular measurement. ${ }^{37,38}$ They were also required to fast for at least $8 \mathrm{~h}$ prior to the evaluation and were advised to wear light and loose clothing. Upon arrival, $6 \mathrm{ml}$ of blood were taken to assess the hematocrit level, fasting blood sugar (FBS), and total cholesterol level. Their height and weight were also obtained. Blood pressure was taken using automated sphygmomanometer (Omron, Kyoto, Japan) in sitting position by the primary investigator (SMIB).

Evaluation of microvascular endothelial dysfunction was conducted in a temperature-controlled room $\left(23-24^{\circ} \mathrm{C}\right)$ in the vascular laboratory, Universiti Sains Malaysia. Dual-channel DRT4 LDF (Moor Instruments, Axminster, UK) with DPIT-V2 skin laser probes (Moor Instruments) was used to measure skin perfusion during iontophoresis. LDF generates a low intensity beam of coherent infrared monochromatic $780 \mathrm{~nm}$ light. This light was delivered to the site of measurement by a flexible fiber optic probe, and it penetrates to a depth of 1-2 mm into the skin. ${ }^{39}$ The blood cells in the tissue beneath the probe generate a continuous flux that is linearly correlated to the underlying blood flow. ${ }^{40}$ When this light beam passes through tissues, it undergoes changes in wavelength as it hits moving blood cells. This change is called Doppler shift. ${ }^{41}$ LDF uses laser Doppler shift principle to measure perfusion of blood cells, mainly erythrocytes, in the skin microvasculature. Theoretically, blood flow, as estimated by LDF, is determined by the blood flow velocity and the number of moving red cell corpuscle within the surface microvessels of the skin. ${ }^{42-44}$

Iontophoresis is a method for non-invasive transdermal drug delivery based on net movements of ions under the influence of small electric current. ${ }^{45}$ This method is based on the principle that charges with the same signal repel and charges with opposite signals attract, facilitating the penetration of ions through the skin. ${ }^{46}$ ACh powder
(Fluka Chemie Gmbh, Tokyo, Japan) and SNP powder (Riedel-de Haen, C.O.O., Buchs, Switzerland) were used as endothelium-dependent and -independent vasodilators, respectively. Sodium chloride solution, $0.9 \%$ at a physiological strength of $0.154 \mathrm{M}$ (Excel Pharmaceutical, Selangor, Malaysia) was used to dilute both drugs to obtain concentrations of $1 \%$ of $\mathrm{ACh}$ and $1 \%$ of SNP. ${ }^{47,38}$ During the $10 \mathrm{~min}$ acclimatization period, patients were advised to lie down straight in bed to minimize the effect of body position. Body position may affect microvascular circulation. The patient's right forearm was exposed and supported by a hand supporter.

Two iontophoresis chambers attached to the surface of the forearm using double adhesive discs were used simultaneously to deliver the ACh (endotheliumdependent vasodilator) and SNP (endotheliumindependent vasodilator) to the skin. The chambers were positioned at least $5 \mathrm{~cm}$ apart so that vasoactive response at one site would not influence the other site. The ACh chamber was attached to the anodal lead while the SNP chamber was attached to the cathodal lead. Each chamber was then filled with $0.4 \mathrm{ml}$ of ACh or SNP, respectively, using a micropipette. Laser probes were carefully inserted with minimal pressure into the chambers. An iontophoresis protocol of five current pulses (lasting 2 min each) separated by 1 min current-free intervals was used. ${ }^{43}$ A current strength of $0.007 \mathrm{~mA}$, density of $0.01 \mathrm{~mA} / \mathrm{cm}^{2}$, and charge density of $6 \mathrm{mC} / \mathrm{cm}^{2}$ were used. ${ }^{43}$ The primary parameters used to assess the microvascular endothelial function were percentage of change in perfusion owing to ACh iontophoresis (\% change) and maximum absolute change in perfusion owing to $\mathrm{ACh}$ iontophoresis $\left(\mathrm{ACh}_{\max }\right)$ as given in these formulas:

$$
\begin{aligned}
\mathrm{ACh} \%= & \text { maximum absolute change in } \mathrm{ACh} \text { perfusion } / \\
& \text { minimum baseline } \mathrm{ACh} \text { perfusion } \times 100 \% . \\
\mathrm{ACh}_{\text {max }}= & \text { maximum increase in } \mathrm{ACh} \text { perfusion at current } \\
& - \text { free period }- \text { minimum baseline } \mathrm{ACh} \text { perfusion. } \\
\mathrm{SNP} \%= & \text { maximum absolute change in SNP perfusion } / \\
& \text { minimum baseline SNP perfusion } \times 100 \% . \\
\mathrm{SNP}_{\text {max }}= & \text { maximum increase in SNP perfusion at current } \\
& - \text { free period }- \text { minimum baseline SNP perfusion } .
\end{aligned}
$$

To ensure reliability of the test, the intraday and interday coefficient of variation (CV) was measured for both ACh $\%$ and $\mathrm{ACh}_{\text {max }}$ on 10 healthy subjects at the start of study. The intraday and interday CV was 13.4 and $13.0 \%$, respectively, for $\mathrm{ACh} \%$.

The data in this study were analyzed using the SPSS version 22.0 software (IBM SPSS, Inc., Chicago, IL, USA). The Pearson chi-square was used to analyze categorical data. One-way analysis of variance (ANOVA) was used to analyze ocular parameters. Endothelium-independent microvascular function according to the severity of POAG 
was analyzed using multiple analysis of variance (ANOVA). Factors previously reported to affect microvascular endothelial function include age, sex, body mass index, hematocrit percentage, total cholesterol levels, FBS levels, diabetes, hypertension, hyperlipidemia and systemic medicines namely, beta blockers, calcium channel blockers, angiotensin-converting enzyme inhibitors, statin and oral hypoglycemic agents. These were used as covariates for endothelial dysfunction. Simple linear regression was applied for covariates. Multiple analysis of covariance (MANCOVA) was used to assess the endothelium-dependent microvascular function and severity of glaucoma.

\section{Informed consent}

Informed consent was obtained from all individual participants enrolled in this study.

\section{Ethical approval}

All procedures performed in this study were in accordance with the ethical standards of the institutional and/or national research committee and with the 1964 Helsinki declaration and its later amendments or comparable ethical standards.

\section{Results}

Based on modified AGIS scoring, Malay patients with POAG were divided into mild (55), moderate (29), and severe (30) stage. POAG patients with severe stage of glaucoma were significantly older than those with moderate or mild stage (Table 1). Systemic hypertension remains the most common systemic comorbidity among our Malay patients. There was a significantly higher percentage of mild severity of POAG with systemic hypertension (Table 1). As expected, significant thinner RNFL, larger average cup disc ratio, larger vertical cup disc ratio, and depressed visual field were observed in patients with severe stage of POAG (Table 1). There was no significant difference in IOP during the recruitment period according to severity of POAG (Table 1).

Confounding factors such as age, sex, hypertension, diabetes mellitus, hyperlipidemia, cardio-vascular systemic diseases, hematocrit, total cholesterol level, and FBS, which may affect the microvascular endothelial function, were analyzed using simple regression analysis and multiple stepwise linear regression (Table 2).

Multiple stepwise linear regressions showed statistically significant negative linear relationship between age and $\mathrm{ACh} \%$. For every additional year of age, there was 11.4 (95\% CI - 22.39, - 0.46) unit decrease in ACh\%.
There was a significant difference in microvascular endothelial function based on severity $(P<0.001)$. There was significant reduction in $\mathrm{ACh} \%$ and $\mathrm{ACh}_{\max }$ values according to severity of POAG (Table 3). In general, POAG patients with severe disease demonstrated lower $\mathrm{ACh} \%$ and $\mathrm{ACh}_{\max }$ values compared with mild and moderate cases. There was a significant negative linear correlation (moderate in strength) between severity and ACh\% $(r=-0.457, P<0.001)$ (Figure 1). Based on post-hoc Bonferroni analysis, differences in $\mathrm{ACh} \%$ and $\mathrm{ACh}_{\max }$ were significant between mild and severe patients and mild and moderate patients (Table 4). There was no significant difference between moderate and severe POAG patients. There was significant difference in $\mathrm{SNP}_{\max }$ according to severity of POAG; patients with severe disease demonstrated lower $\mathrm{SNP}_{\max }$ (Table 3). Based on post-hoc Bonferroni analysis, there was significant difference in $\mathrm{SNP}_{\max }$ between mild and severe POAG (Table 4).

\section{Discussion}

In the current study, there was significant association between peripheral microvascular endothelial function $\left(\mathrm{ACh} \%\right.$ and $\mathrm{ACh}_{\max }$ ) and severity of POAG in Malay patients. Long-standing POAG is associated with progression to severe disease. ${ }^{48}$ Thus it is not surprising that Malay patients with severe POAG were older. Age was also identified as a significant confounding factor affecting microvascular endothelial function in this study. Unlike arteriosclerotic changes that increase with age, microvascular endothelial function was reported to reduce with age. ${ }^{49}$ There was 11.4 (95\% CI - 22.39, - 0.46) units reduction of $\mathrm{ACh} \%$ for every additional year of age.

Perhaps, for similar reason, systemic hypertension was found to be the most common systemic comorbidity in this study. However, there was significantly higher number of patients with hypertension in mild stage of POAG. In general, systemic comorbidities appear to be more common in mild stage of POAG in our study. It was found that the presence of systemic diseases such as hypertension lead to early detection of POAG. ${ }^{50,51}$ Perhaps, the association between systemic comorbidities and severity of POAG is due to early detection rather than as part of pathogenesis of POAG. Nevertheless, to eliminate the potential effect of systemic hypertension and antihypertensive medications on microvascular endothelial function, our result was further adjusted for systemic hypertension, systemic medications, and other comorbidities.

In addition, systemic comorbidities were not found to be a significant predictor for microvascular endothelial function in this study. On the contrary, reduction of microvascular endothelial function was observed in 
Table 1 Comparison of demographic and clinical data between mild, moderate, and severe POAG in Malay patients

\begin{tabular}{|c|c|c|c|c|}
\hline Demographic characteristics & Mild, $\mathrm{N}=55$ & Moderate, $\mathrm{N}=29$ & Severe, $\mathrm{N}=30$ & P-value \\
\hline \multicolumn{5}{|l|}{$\operatorname{Sex}(n(\%))$} \\
\hline Male & $37(52.9 \%)$ & $15(21.4 \%)$ & $18(25.7 \%)$ & \multirow[t]{2}{*}{$0.373^{\mathrm{a}}$} \\
\hline Female & $18(40.9 \%)$ & $14(31.8 \%)$ & $12(27.3 \%)$ & \\
\hline Age, years (mean (SD) & $64.2(8.5)$ & $68.6(8.9)$ & $70.1(7.4)$ & $0.004^{\mathrm{b}}$ \\
\hline \multicolumn{5}{|l|}{ Systemic diseases $(n, \%)$} \\
\hline Hypertension & $39(51.3 \%)$ & $23(30.3 \%)$ & $14(18.4 \%)$ & $0.019^{\mathrm{a}}$ \\
\hline Diabetes mellitus & $23(54.8 \%)$ & $12(28.6 \%)$ & $7(16.7 \%)$ & $0.202^{\mathrm{a}}$ \\
\hline Hyperlipidemia & $27(57.4 \%)$ & $13(27.7 \%)$ & $7(14.9 \%)$ & $0.063^{\mathrm{a}}$ \\
\hline Body mass index, $\mathrm{kg} / \mathrm{m}^{2}$ (mean (SD)) & $25.2(4.3)$ & $24.3(3.5)$ & $24.3(4.9)$ & $0.484^{\mathrm{b}}$ \\
\hline \multicolumn{5}{|l|}{ Ocular parameters (mean $(S D)$ ) } \\
\hline Central corneal thickness $(\mu \mathrm{m})$ & $520.8(23.6)$ & $518.1(28.6)$ & $514.8(29.8)$ & $0.683^{\mathrm{b}}$ \\
\hline IOP at recruitment $(\mathrm{mm} \mathrm{Hg})$ & $16.3(3.2)$ & $15.7(3.4)$ & $17.5(5.2)$ & $0.183^{\mathrm{b}}$ \\
\hline Retinal nerve fiber layer thickness $(\mu \mathrm{m})$ & $72.014 .6)$ & $66.3(14.9)$ & $56.6(10.3)$ & $<0.001^{\mathrm{b}}$ \\
\hline Rim area $\left(\mathrm{mm}^{2}\right)$ & $0.87(0.3)$ & $0.75(0.1)$ & $0.63(0.4)$ & $0.011^{\mathrm{b}}$ \\
\hline Vertical cup disc ratio & $0.75(0.07)$ & $0.78(0.05)$ & $0.83(0.08)$ & $<0.001^{\mathrm{b}}$ \\
\hline Average cup disc ratio & $0.77(0.09)$ & $\begin{array}{lll}0.80 & 0.04)\end{array}$ & $0.83(0.06)$ & $0.001^{\mathrm{b}}$ \\
\hline \multicolumn{5}{|l|}{ Humphrey visual field } \\
\hline Mean deviation & $-4.02 .0)$ & $-10.1(3.1)$ & $-24.3(4.4)$ & $<0.001^{\mathrm{b}}$ \\
\hline Pattern SD & $4.4(2.3)$ & $8.1(3.0)$ & $9.4(2.6)$ & $<0.001^{\mathrm{b}}$ \\
\hline \multicolumn{5}{|l|}{ Systemic medicines $(n(\%))$} \\
\hline Calcium channel blockers & $23(50 \%)$ & $14(30.4 \%)$ & $9(19.5 \%)$ & $0.343^{\mathrm{a}}$ \\
\hline Beta blockers & $8(57.1 \%)$ & $4(28.5 \%)$ & $2(14.2 \%)$ & $0.548^{\mathrm{a}}$ \\
\hline ACEi & $10(47.6 \%)$ & $5(23.8 \%)$ & $6(28.5 \%)$ & $0.971^{\mathrm{a}}$ \\
\hline Statins & $25(43.8 \%)$ & $15(26.3 \%)$ & $17(29.8 \%)$ & $0.058^{\mathrm{a}}$ \\
\hline OHA & $18(51.4 \%)$ & $12(34.2 \%)$ & $5(14.2 \%)$ & $0.109^{\mathrm{a}}$ \\
\hline \multicolumn{5}{|l|}{ Topical medicines $(n(\%))$} \\
\hline Beta blockers & $35(46.0 \%)$ & $20(26.3 \%)$ & $21(27.6 \%)$ & $0.800^{\mathrm{a}}$ \\
\hline Carbonic anhydrase inhibitors & $14(38.8 \%)$ & $10(27.7 \%)$ & $12(33.3 \%)$ & $0.358^{\mathrm{a}}$ \\
\hline Prostaglandin analogs & $39(43.3 \%)$ & $25(27.7 \%)$ & $26(28.8 \%)$ & $0.127^{\mathrm{a}}$ \\
\hline Alpha-2 agonist & $01(33.3 \%)$ & $0(0 \%)$ & $02(66.6 \%)$ & $0.243^{\mathrm{a}}$ \\
\hline
\end{tabular}

Abbreviations: ACEi, angiotensin-converting enzyme inhibitors; OHA, oral hypoglycemic agent. ${ }^{a} P<0.05$ is considered statistically significant based on Pearson's chi-square. ${ }^{b} P<0.05$ is considered statistically significant based on one-way ANOVA. Bold values indicate significant values.

Table 2 Simple linear regression between predictors affecting acetylcholine \% (endothelial function)

\begin{tabular}{|c|c|c|c|c|}
\hline $\mathrm{N}=114$ & Coefficient B & $95 \% \mathrm{CI}$ & T-stat & P-value \\
\hline Age (years) & -11.90 & $-22.83,-0.96$ & -2.15 & 0.033 \\
\hline Sex & -104.61 & $-302.06,92.83$ & -1.05 & 0.296 \\
\hline Hypertension & -84.22 & $-288.52,120.08$ & -0.81 & 0.416 \\
\hline Diabetes mellitus & -69.00 & $-268.83,130.83$ & -1.71 & 0.089 \\
\hline $\mathrm{CVS}^{\mathrm{a}}$ & 55.34 & $-203.64,314.33$ & 0.42 & 0.673 \\
\hline Hyperlipidemia & -30.18 & $-226.33,165.97$ & -0.30 & 0.761 \\
\hline Systolic blood pressure $(\mathrm{mm} \mathrm{Hg})$ & -1.68 & $-7.28,3.90$ & -0.59 & 0.551 \\
\hline Diastolic blood pressure $(\mathrm{mm} \mathrm{Hg})$ & -3.16 & $-14.51,8.18$ & -0.55 & 0.582 \\
\hline Body mass index $\left(\mathrm{kg} / \mathrm{m}^{2}\right)$ & 3.14 & $-19.38,25.67$ & 0.27 & 0.783 \\
\hline Hematocrit \% & -14.39 & $-36.57,7.78$ & -1.28 & 0.201 \\
\hline Total cholesterol (mmol/l) & -5.52 & $-89.44,78.39$ & -0.13 & 0.896 \\
\hline Fasting blood sugar $(\mathrm{mmol} / \mathrm{l})$ & 1.49 & $-31.54,34.54$ & 0.09 & 0.929 \\
\hline
\end{tabular}

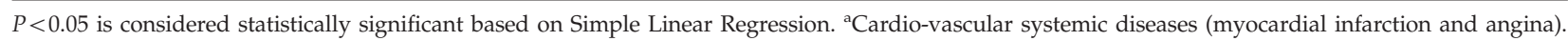
Bold values indicate significant values. 
Table $3 \mathrm{ACh} \%, \mathrm{ACh}_{\max }, \mathrm{SNP} \%$ and $\mathrm{SNP}_{\max }$ and severity of POAG in Malay patients

\begin{tabular}{|c|c|c|c|c|c|}
\hline & \multicolumn{3}{|c|}{ Severity } & \multirow[t]{2}{*}{$\mathrm{F}$} & \multirow[t]{2}{*}{ P-value } \\
\hline & Mild, $\mathrm{N}=55$ & Moderate, $\mathrm{N}=29$ & Severe, $\mathrm{N}=30$ & & \\
\hline \multicolumn{6}{|l|}{ Acetylcholine (ACh)-mediated response } \\
\hline ACh\% (mean, 95\% CI) & $715.8(588.3,843.3)$ & $372.1(196.5,547.7)$ & $239.9(67.3,412.6)$ & 11.1 & $<0.001^{\mathrm{a}}$ \\
\hline${ }^{\mathrm{b}} \mathrm{ACh} \%$ (mean, 95\% CI) & $712.9(573.6,852.3)$ & $391.2(200.3,582.1)$ & $224.5(27.4,421.7)$ & 8.2 & $0.001^{\mathrm{c}}$ \\
\hline $\mathrm{ACh}_{\max }(\mathrm{AU})($ mean, $95 \% \mathrm{CI})$ & $51.1(44.0,58.1)$ & $28.7(19.0,38.4)$ & $18.6(9.1,27.6)$ & 16.9 & $<0.001^{*}$ \\
\hline${ }^{\mathrm{b}} \mathrm{ACh}_{\max }($ mean, $95 \% \mathrm{CI})$ & $52.2(44.7,59.7)$ & $25.8(15.5,36.1)$ & $19.1(8.5,29.7)$ & 14.4 & $<0.001^{\mathrm{c}}$ \\
\hline \multicolumn{6}{|c|}{ Sodium nitroprusside (SNP)-mediated response } \\
\hline $\mathrm{SNP} \%$ (mean, $95 \% \mathrm{CI})$ & $937.6(824.1,1051.1)$ & $732.0(575.7,888.2)$ & $765.6(612.0,919.3)$ & 2.8 & $0.062^{*}$ \\
\hline $\mathrm{SNP}_{\max }(\mathrm{AU})($ mean, $95 \% \mathrm{CI})$ & $77.7(68.8,86.5)$ & $62.0(49.8,74.1)$ & $53.1(41.1,65.0)$ & 5.9 & $0.004^{*}$ \\
\hline
\end{tabular}

${ }^{a} P<0.05$ is considered statistically significant based on MANOVA. ${ }^{\mathrm{b}}$ Adjusted for age, sex, hypertension, diabetes mellitus, hyperlipidemia, cardio-vascular systemic diseases, systolic blood pressure, diastolic blood pressure, body mass index, hematocrit, total cholesterol, fasting blood sugar, calcium channel blockers, beta blockers, angiotensin-converting enzyme inhibitors, statins, and oral hypoglycemic agents. ${ }^{c} P<0.05$ is considered statistical significant based on MANCOVA. Bold values indicate significant values.

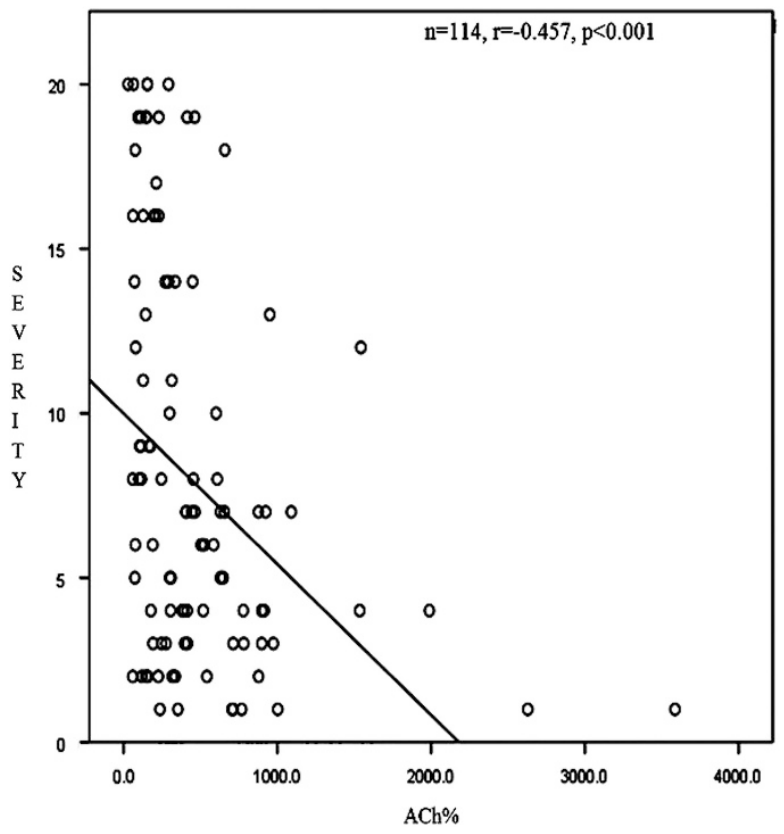

Figure 1 Correlation analysis between severity of POAG and Ach\%.

hypertension, diabetes, and hypercholesterolemia in Caucasians. ${ }^{52}$ Ethnicity has been found to be associated with microvascular endothelial function in heart failure patients even after the adjustment for age, presence of systemic hypertension and diabetes mellitus, blood pressure, and glucose levels. ${ }^{53}$

To the best of our knowledge, this is the only study on peripheral microvascular endothelial function and severity of POAG using LDF and the process of iontophoresis. ACh stimulates membrane receptor on the surface of endothelial cells leading to an increase in intracellular calcium, which in turn activates the enzyme endothelial nitric oxide (NO) synthase to produce NO.
Table 4 Pair wise comparison of $\mathrm{ACh} \%, \mathrm{ACh}_{\max }, \mathrm{SNP} \%$, and $\mathrm{SNP}_{\max }$ according to severity

\begin{tabular}{|c|c|c|}
\hline Severity & & P-value \\
\hline \multicolumn{3}{|l|}{${ }^{\mathrm{a}} \mathrm{Ach} \%$, mean $(95 \% \mathrm{CI})$} \\
\hline Mild to moderate & $321.7(23.9,619.5)$ & $0.030^{\mathrm{b}}$ \\
\hline Moderate to severe & $166.6(152.3,508.3)$ & $0.712^{\mathrm{b}}$ \\
\hline Mild to severe & $488.4(178.2,798.6)$ & $0.001^{\mathrm{b}}$ \\
\hline \multicolumn{3}{|l|}{${ }^{\mathrm{a}} A C h_{\max }$, mean $(95 \% \mathrm{CI})$} \\
\hline Mild to moderate & $26.4(10.3,42.4)$ & $<0.001^{\mathrm{b}}$ \\
\hline Moderate to severe & $6.7(11.7,25.1)$ & $1.000^{\mathrm{b}}$ \\
\hline Mild to severe & $33.1(16.3,49.8)$ & $<0.001^{\mathrm{b}}$ \\
\hline \multicolumn{3}{|l|}{ SNP\%, mean $(95 \% \mathrm{CI})$} \\
\hline Mild to moderate & $205.6(31.2,442.5)$ & $0.111^{\mathrm{c}}$ \\
\hline Moderate to severe & $33.6(235.1,302.4)$ & $1.000^{c}$ \\
\hline Mild to severe & $171.9(62.3,406.2)$ & $0.231^{\mathrm{c}}$ \\
\hline \multicolumn{3}{|l|}{$S N P_{\max }$, mean $(95 \% \mathrm{CI})$} \\
\hline Mild to moderate & $15.6(2.7,34.1)$ & $0.123^{c}$ \\
\hline Moderate to severe & $8.9(11.9,29.8)$ & $0.896^{\mathrm{c}}$ \\
\hline Mild to severe & $24.6(6.4,42.8)$ & $0.004^{c}$ \\
\hline
\end{tabular}

${ }^{a}$ Adjusted for age, sex, hypertension, diabetes mellitus, hyperlipidemia, cardio-vascular systemic diseases, systolic blood pressure, diastolic blood pressure, body mass index, hematocrit, total cholesterol, fasting blood sugar, calcium channel blockers, beta blockers, angiotensin-converting enzyme inhibitors, statins, and oral hypoglycaemic agents. ${ }^{b} P<0.05$ is considered statistically significant based on adjustment of multiple comparison with Bonferroni correction. ${ }^{c} P<0.05$ is considered statistically significant based on post-hoc test with Bonferroni correction. Bold values indicate significant values.

The released NO reaches its target organ (vascular smooth muscle cells) and activates the enzyme guanylate cyclase, which is responsible for the production of cyclic guanosine monophosphate (cGMP) leading to a decrease in calcium thereby causing vasodilatation. ${ }^{54,55} \mathrm{SNP}$ is a direct vasodilator, with equal arterial and venous effects. ${ }^{56}$ SNP stimulates the synthesis of cGMP in smooth muscle that leads to the formation of NO radicals. 
These radicals initiate a chain of events that lead to dephosphorylation of contractile proteins in smooth muscle, causing relaxation and vasodilatation. ${ }^{57}$

In the current study, data were controlled for potential confounding factors as shown in Table 3 using the MANCOVA statistical analysis. There was reduction in peripheral microvascular endothelial function (as reflected by endothelium-mediated vasodilatation) according to severity of POAG even after controlling for age and other potential confounders, including systemic diseases and systemic medications. This is an indirect quantification of microvascular endothelial function with the assumption that similar endothelial dysfunction occurs in the ocular circulation. ${ }^{58,59}$ There was also difference in endothelium-independent vasodilatation $\left(\mathrm{SNP}_{\max }\right)$ between mild and severe POAG. This may indicate impairment of vascular smooth muscle relaxation in microcirculation with severe POAG. Endothelial dysfunction affecting release of endothelial vasoconstrictor and vasodilators supplying the optic nerve head may cause impairment of perfusion leading to RNFL damage. ${ }^{60-64}$

Microvascular endothelial dysfunction and impairment of vascular smooth muscle relaxation may accelerate glaucomatous damage responsible for more severe glaucoma in the current study. Trabecular meshwork is also lined by the endothelium. ${ }^{65}$ Any abnormalities or dysfunction of the peripheral endothelium may directly contribute to changes in trabecular meshwork and disturbance in aqueous outflow. ${ }^{66-69}$ Although this postulation is not thoroughly conclusive, endothelial dysfunction may affect $\mathrm{ONH}$ perfusion and impair the aqueous outflow.

Endothelial function in the peripheral vessels and end arteries in the eye may differ. The retinal arteries lose their internal elastic lamina as they bifurcate at optic disc. ${ }^{70,71}$ That differentiates them from vasculature of other tissues, and as a compensatory mechanism, they have thicker muscularis layer. Thicker muscularis of retinal arteries leads to more vasodilatation in response to chemical stimuli. ${ }^{71}$ The endothelial cells of retinal arteries are not fenestrated and linked by tight junctions, but in peripheral vessels there are no tight junctions. ${ }^{72}$ There may be other factors that affect the blood perfusion to ONH contributing to glaucomatous optic neuropathy. Direct evaluation of ocular endothelial function is not possible with current methodologies. The technique adopted in this study allowed indirect evaluation of eye vessel microvascular endothelial function.

Imbalanced distribution in the number of POAG patients according to severity is a possible confounding factor in this study. There were more patients with mild stage compared with severe-stage POAG. There is a possibility that by chance patients with reduction of peripheral microvascular endothelial function may have been recruited among POAG patients with severe disease. An equal distribution of patients according to severity of the disease may eliminate these biases. ${ }^{73}$

In conclusion, there is a potential role of peripheral microvascular endothelial function as a predictor for the severity of POAG in Malay patients. Impairment in peripheral endothelial-dependent vasodilatation may lead to inadequate perfusion and acceleration in glaucomatous damage.

\section{Summary}

What was known before

- Microvascular endothelial dysfunction is associated with primary open angle glaucoma.

What this study adds

- Microvascular endothelial dysfunction may have a role in the severity of primary open angle glaucoma in Malay patients.

\section{Conflict of interest}

The authors declare no conflict of interest.

\section{Acknowledgements}

This work was supported in parts by Universiti Sains Malaysia Research University Individual grant no. 1001\ PPSP $\backslash 812101$, Universiti Sains Malaysia, Health campus, Kelantan, Malaysia.

\section{References}

1 Fechtner RD, Weinreb RN. Mechanisms of optic nerve damage in primary open angle glaucoma. Surv Ophthalmol 1994; 39(1): 23-42.

2 Hayreh SS. Factors influencing blood flow in the optic nerve head. J Glaucoma 1997; 6(6): 412-425.

3 Flammer J, Haefliger IO, Orgul S, Resink T. Vascular dysregulation: a principal risk factor for glaucomatous damage? J Glaucoma 1999; 8(3): 212-219.

4 Flammer J. The vascular concept of glaucoma. Surv Ophthalmol 1994; 38: S3-S6.

5 Aspinall P. Measurement of ocular blood flow velocity using colour Doppler imaging in low tension glaucoma. Eye 1995; 9: 29-33.

6 Ohnishi Y, Fujisawa K, Ishibashi T, Kojima H. Capillary blood flow velocity measurements in cystoid macular edema with the scanning laser ophthalmoscope. Am J Ophthalmol 1994; 117(1): 24-29.

7 Garzozi HJ, Shoham N, Chung HS, Kagemann L, Harris A. Ocular blood flow measurements and their importance in glaucoma and age-related macular degeneration. Isr Med Assoc J 2001; 3(6): 443-448.

8 Nguyen TT, Kreis AJ, Kawasaki R, Wang JJ, Seifert B-U, Vilser W et al. Reproducibility of the retinal vascular 
response to flicker light in Asians. Curr Eye Res 2009; 34(12): 1082-1088.

9 Abdallah W, Fawzi A, Patel H, Dagliyan G, Matsuoka N, Grant E et al. Blood velocity measurement in the posterior segment of the rabbit eye using combined spectral Doppler and power Doppler ultrasound. Graefes Arch Clin Exp Ophthalmol 2010; 248(1): 93-101.

10 Harris LKA. Measuring ocular blood flow. 2009; http:// glaucomatoday.com/2009/04/GT0409_08.php/. Accessed 2 February 2016.

11 Roorda A. Applications of adaptive optics scanning laser ophthalmoscopy. Optom Vis Sci 2010; 87(4): 260.

12 Garhofer G, Bek T, Boehm AG, Gherghel D, Grunwald J, Jeppesen $\mathrm{P}$ et al. Use of the retinal vessel analyzer in ocular blood flow research. Acta Ophthalmol 2010; 88(7): 717-722.

13 Gramatikov BI. Modern technologies for retinal scanning and imaging: an introduction for the biomedical engineer. Biomed Eng 2014; 13(1): 52.

14 Blum M, Bachmann K, Wintzer D, Riemer T, Vilser W, Strobel J. Noninvasive measurement of the Bayliss effect in retinal autoregulation. Graefes Arch Clin Exp Ophthalmol 1999; 237(4): 296-300.

15 Schallenberg M, Kremmer S, Anastassiou G, Steuhl K, Selbach J. Correlation of retinal vessel analysis and nerve fiber layer thickness in normal tension glaucoma. J Clin Exp Ophthalmol 2015; 6: 497.

16 Garhofer G, Zawinka C, Resch H, Huemer KH, Schmetterer L, Dorner GT. Response of retinal vessel diameters to flicker stimulation in patients with early open angle glaucoma. J Glaucoma 2004; 13(4): 340-344.

17 Flammer J, Pache M, Resink T. Vasospasm, its role in the pathogenesis of diseases with particular reference to the eye. Prog Retin Eye Res 2001; 20(3): 319-349.

18 Moore D, Harris A, WuDunn D, Kheradiya N, Siesky B. Dysfunctional regulation of ocular blood flow: a risk factor for glaucoma. Clin Ophthalmol 2008; 2(4): 849-861.

19 Johnson PC. Brief review: autoregulation of blood flow. Circ Res 1986; 59: 483-495.

20 Pournaras CJ, Rungger-Brändle E, Riva CE, Hardarson SH, Stefansson E. Regulation of retinal blood flow in health and disease. Prog Retin Eye Res 2008; 27(3): 284-330.

21 Takagi C, King GL, Takagi H, Lin Y-W, Clermont AC, Bursell S-E. Endothelin-1 action via endothelin receptors is a primary mechanism modulating retinal circulatory response to hyperoxia. Invest Ophthalmol Vis Sci 1996; 37(10): 2099-2109.

22 Busse R, Lackhoff A, Bassenge E. Endothelium-derived relaxant factor inhibits platelet activation. Naunyn Schmiedebergs Arch Pharmacol 1987; 336(5): 566-571.

23 Harder DR. Pressure-induced myogenic activation of cat cerebral arteries is dependent on intact endothelium. Circ Res 1987; 60(1): 102-107.

24 Schmidl D, Garhofer G, Schmetterer L. The complex interaction between ocular perfusion pressure and ocular blood flow - relevance for glaucoma. Exp Eye Res 2011; 93(2): 141-155.

25 Luo X, Shen Y-m, Jiang M-n, Lou X-f, Shen Y. Ocular blood flow autoregulation mechanisms and methods. J Ophthalmol 2015; 2015: 864871.

26 Rossitti S, Frangos J, Girard PR, Bevan J. Regulation of vascular tone. Can J Physiol Pharmacol 1995; 73(5): 544-550.

27 Yvonne-Tee GB, Rasool AHG, Halim AS, Wong AR, Rahman ARA. Method optimization on the use of postocclusive hyperemia model to assess microvascular function. Clin Hemorheol Microcirc 2008; 38(2): 119-133.

28 Almond N. Laser Doppler flowmetry: instrumentation theory and practice. In: Belcaro G (ed), Vascular Diagnosis, 1996. Med-Orion: London.

29 Yvonne-Tee GB, Rasool AHG, Halim AS, Rahman ARA. Noninvasive assessment of cutaneous vascular function in vivo using capillaroscopy, plethysmography and laser-Doppler instruments: its strengths and weaknesses. Clin Hemorheol Microcirc 2006; 34(4): 457-473.

30 Su WW, Cheng ST, Ho WJ, Tsay PK, Wu SC, Chang SHL. Glaucoma is associated with peripheral vascular endothelial dysfunction. Ophthalmology 2008; 115(7): 1173-1178.

31 Yamazaki Y, Drance SM. The relationship between progression of visual field defects and retrobulbar circulation in patients with glaucoma. Am J Ophthalmol 1997; 124(3): 287-295.

32 Kaiser HJ, Schoetzau A, Stümpfig D, Flammer J. Blood-flow velocities of the extraocular vessels in patients with high-tension and normal-tension primary open-angle glaucoma. Am J Ophthalmol 1997; 123(3): 320-327.

33 Yip JL, Foster PJ. Ethnic differences in primary angle-closure glaucoma. Curr Opin Ophthalmol 2006; 17(2): 175-180.

34 Wilson R, Richardson T, Hertzmark E, Grant W. Race as a risk factor for progressive glaucomatous damage. Ann ophthalmol 1985; 17(10): 653-659.

35 APGS. Asia Pacific Glaucoma Guidelines, 2nd edn. (2008) http://www.icoph.org/dynamic/attachments/resources/ asia-pacific_glaucoma_guidelines.pdf. Accessed 7 July 2015.

36 AGIS AGISI. Advanced Glaucoma Intervention Study: 2. Visual field test scoring and reliability. Ophthalmology 1994; 101(8): 1445-1455.

37 Al-Tahami BAM, Ismail AAA-S, Bee YTG, Awang SA, Rani SWA, Rimei W et al. The effects of anti-obesity intervention with orlistat and sibutramine on microvascular endothelial function. Clin Hemorheol Microcirc 2015; 59(4): 323-334.

38 Al-Tahami BA, Bee Y-TG, Ismail AAA-S, Rasool AHG. Impaired microvascular endothelial function in relatively young obese humans is associated with altered metabolic and inflammatory markers. Clin Hemorheol Microcirc 2011; 47(2): 87-97.

39 Anderson R, Parrish J. Optical properties of human skin. In: The Science of Photomedicine. Springer: USA, 1982; pp 147-194.

40 Ahn H, Johansson K, Lundgren O, Nilsson G. In vivo evaluation of signal processors for laser Doppler tissue flowmeters. Med Biol Eng Comput 1987; 25(2): 207-211.

41 Sarnik S, Hofirek I, Sochor O. Laser Doppler fluxmetry. Biomedical Papers of the Medical Faculty of Palacky University in Olomouc 2007; 151(1): 143-146.

42 Nilsson GE, Tenland T, Oberg PA. Evaluation of a laser Doppler flowmeter for measurement of tissue blood flow. IEEE Trans Biomed Eng 1980; 27(10): 597-604.

43 Al-Tahami BA, Yvonne-Tee GB, Halim AS, Ismail AA, Rasool AH. Reproducibility of laser Doppler fluximetry and the process of iontophoresis in assessing microvascular endothelial function using low current strength. Methods Find Exp Clin Pharmacol 2010; 32(3): 181-185.

44 Al-Tahami Belqes TG, Halim AS, Al-Safi AA, AHG Rasool. Method optimisation of laser doppler fluximetry and iontophoresis in assessment of microvascular endothelial function. Mal J Med Health Sci 2011; 7(1): 35-40. 
45 Roustit M, Cracowski JL. Non-invasive assessment of skin microvascular function in humans: an insight into methods. Microcirculation 2012; 19(1): 47-64.

46 Krueger E, Claudino Jr JL, Scheeren EM, Neves EB, Mulinari E, Nohama P. Iontophoresis: principles and applications. Fisioter Mov 2014; 27(3): 469-481.

47 Droog EJ, Henricson J, Nilsson GE, Sjöberg F. A protocol for iontophoresis of acetylcholine and sodium nitroprusside that minimises nonspecific vasodilatory effects. Microvasc Res 2004; 67(2): 197-202.

48 Mbadugha CA, Onakoya AO. The awareness, perceptions and experiences of primary open angle glaucoma patients in Lagos Nigeria. Sci Rep 2014; 4: 7585.

49 Celermajer DS, Sorensen KE, Spiegelhalter DJ, Georgakopoulos D, Robinson J, Deanfield JE. Aging is associated with endothelial dysfunction in healthy men years before the age-related decline in women. J Am Coll Cardiol 1994; 24(2): 471-476.

50 Dielemans I, Vingerling JR, Algra D, Hofman A, Grobbee DE, de Jong PT. Primary open-angle glaucoma, intraocular pressure, and systemic blood pressure in the general elderly population. The Rotterdam Study. Ophthalmology 1995; 102(1): 54-60.

51 Tielsch JM, Katz J, Sommer A, Quigley HA, Javitt JC. Hypertension, perfusion pressure, and primary open-angle glaucoma. A population-based assessment. Arch Ophthalmol 1995; 113(2): 216-221.

52 Benjamin EJ, Larson MG, Keyes MJ, Mitchell GF, Vasan RS, Keaney JF Jr et al. Clinical correlates and heritability of flow-mediated dilation in the community: the Framingham Heart Study. Circulation 2004; 109(5): 613-619.

53 Shantsila E, Wrigley B, Shantsila A, Tapp LD, Blann AD, Gill PS et al. Ethnic differences in macrovascular and microvascular function in systolic heart failure. Circ Heart Fail 2011; 4(6): 754-762.

54 Haefliger IO, Meyer P, Flammer J, Lüscher TF. The vascular endothelium as a regulator of the ocular circulation: a new concept in ophthalmology? Surv Ophthalmol 1994; 39(2): 123-132.

55 Haefliger I, Zschauer A, Anderson DR. Relaxation of retinal pericyte contractile tone through the nitric oxide-cyclic guanosine monophosphate pathway. Invest Ophthalmol Vis Sci 1994; 35(3): 991-997.

56 Benowitz NL BH. Antihypertensive Agents. Basic Clinical Pharmacology, 3rd edn. Appleton-Lange: Norwalk, Connecticut, USA, 1986.

57 Walker HJ, Geniton DJ. Vasodilator therapy and the anesthetist: a review of nitroprusside, labetalol, hydralazine and nitroglycerin. AANA J 1989; 57(5): 435-444.

58 Kaski JC, Eslick GD, Merz CNB. Chest Pain with Normal Coronary Arteries: A Multidisciplinary Approach. Springer Science \& Business Media, 2013.
59 Schmetterer L, Kiel J. Ocular Blood Flow. Springer Science \& Business Media: Heidelberg New York Dordrecht London, 2012.

60 Haefliger IO, Meyer P, Flammer J, Lüscher TF. The vascular endothelium as a regulator of the ocular circulation: a new concept in ophthalmology? Surv Ophthalmol 1994; 39(2): 123-132.

61 Haefliger IO, Dettmann E, Liu R, Meyer P, Prünte C, Messerli J et al. Potential role of nitric oxide and endothelin in the pathogenesis of glaucoma. Surv Ophthalmol 1999; 43: S51-S58.

62 Findl O, Rainer G, Dallinger S, Dorner G, Polak K, Kiss B et al. Assessment of optic disk blood flow in patients with open-angle glaucoma. Am J Ophthalmol 2000; 130(5): 589-596.

63 Delaney Y, Walshe TE, O'Brien C. Vasospasm in glaucoma: clinical and laboratory aspects. Optom Vis Sci 2006; 83(7): 406-414.

64 Resch H, Garhofer G, Fuchsjäger-Mayrl G, Hommer A, Schmetterer L. Endothelial dysfunction in glaucoma. Acta Ophthalmol 2009; 87(1): 4-12.

65 Llobet A, Gasull X, Gual A. Understanding trabecular meshwork physiology: a key to the control of intraocular pressure? News Physiol Sci 2003; 18(5): 205-209.

66 Alvarado JA, Yeh RF, Franse-Carman L, Marcellino G, Brownstein MJ. Interactions between endothelia of the trabecular meshwork and of Schlemm's canal: a new insight into the regulation of aqueous outflow in the eye. Trans Am Ophthalmol Soc 2005; 103: 148-162 (discussion 159-161).

67 Fadini GP, Pagano C, Baesso I, Kotsafti O, Doro D, De Kreutzenberg SV et al. Reduced endothelial progenitor cells and brachial artery flow-mediated dilation as evidence of endothelial dysfunction in ocular hypertension and primary open-angle glaucoma. Acta Ophthalmol 2010; 88(1): 135-141.

68 Alvarado J, Murphy C, Juster R. Trabecular meshwork cellularity in primary open-angle glaucoma and nonglaucomatous normals. Ophthalmology 1984; 91(6): 564-579.

69 Saccà SC, Centofanti M, Izzotti A. New proteins as vascular biomarkers in primary open angle glaucomatous aqueous humor. Invest Ophthalmol Vis Sci 2012; 53(7): 4242-4253.

70 Dartt DA, Dana R, D'Amore P. Immunology, Inflammation and Diseases of the Eye. Academic Press, 2011.

71 Anand-Apte B, Hollyfield J. Developmental Anatomy of the Retinal and Choroidal Vasculature. Encyclopedia of the Eye. Academic Press, Elsevier Books: London, UK, 2010; 9-15.

72 Besharse JC, Bok D. The Retina and its Disorders. Academic Press: San Diego, CA, USA, 2011.

73 Pannucci CJ, Wilkins EG. Identifying and avoiding bias in research. Plast Reconstr Surg 2010; 126(2): 619-625. 